\title{
Study of Cosmogenic Radionuclides Formed By Cosmic Ray Spallations in Quartz Samples
}

\author{
Ashok Kumar ${ }^{1}$, Rajeev Ranjan Sinha ${ }^{1}$, Swapan Kumar Bera ${ }^{2}$ \\ ${ }^{1}$ S.K.M.University, Dumka \\ ${ }^{2}$ Jharkhand Rai University, Ranchi
}

\begin{abstract}
The present research work aims to analyze the cosmogenic radionuclide like ${ }^{10} \mathrm{Be},{ }^{14} \mathrm{C},{ }^{36} \mathrm{Cl},{ }^{41} \mathrm{Ca}$ etc obtained in various previous research formed by cosmic ray spallations in quartz samples theoretically. It has been tried to come to the conclusion that the nature of the quartz samples for the study of cosmogenic radionuclides almost looks alike and their graphs for the ratio of radio isotopes to the stable isotope and the average age of the sample by the dating through various isotopes are similar.
\end{abstract}

Key words: Cosmogenic radionuclides, Accelerator Mass Spectrometry

\section{Introduction}

As the proposed research aims to analyze the cosmogenic radionuclide like ${ }^{10} \mathrm{Be},{ }^{14} \mathrm{C},{ }^{36} \mathrm{Cl},{ }^{41} \mathrm{Ca}$ etc obtained in various previous research formed by cosmic ray spallations in quartz $\left(\mathrm{SiO}_{2}\right)$, a ubiquitous material formed among a variety of rocks exposed in the surface of the hilly region theoretically.

\section{Methodology}

The theoretical analysis has been done by comparing the tabulated findings of" Determination of Cosmogenic radionuclide's in the quartz samples of the plateau region by A.M.S. (R.R. Sinha \& T. Nandi)" and the results at the Isotrace laboratory where the procedures were developed for ${ }^{14} \mathrm{C}$ A.M.S. to produce precision of $0.2 \%$ or \pm 16 years in which case, the result at those precision were found to be reproducible and accurate (R.P. Beukens, Procedures \& precision in ${ }^{14} \mathrm{C}$ A.M.S.). The result of obtained cosmogenic radionuclide ${ }^{14} \mathrm{C}$ from the quartz sample of hilly regions Jharkhand in India as follows:

\begin{tabular}{|l|l|l|l|}
\hline Sample & Average Concentration & ${ }^{14} \mathrm{C} /{ }^{12} \mathrm{C}$ & Age \\
\hline 1 & $1.225 \times 10^{9}$ & $66.00 \times 10^{-15}$ & $4.748 \times 10^{4}$ years \\
\hline 2 & $1.2030 \times 10^{9}$ & $58.019 \times 10^{-15}$ & $4.7491 \times 10^{4}$ years \\
\hline 3 & $1.2174 \times 10^{9}$ & $64.23 \times 10^{-15}$ & $4.7486 \times 10^{4}$ years \\
\hline 4 & $1.2135 \times 10^{9}$ & $66.022 \times 10^{-15}$ & $4.7487 \times 10^{4}$ years \\
\hline 5 & $1.2233 \times 10^{9}$ & $62.022 \times 10^{-15}$ & $4.7478 \times 10^{4}$ years \\
\hline
\end{tabular}

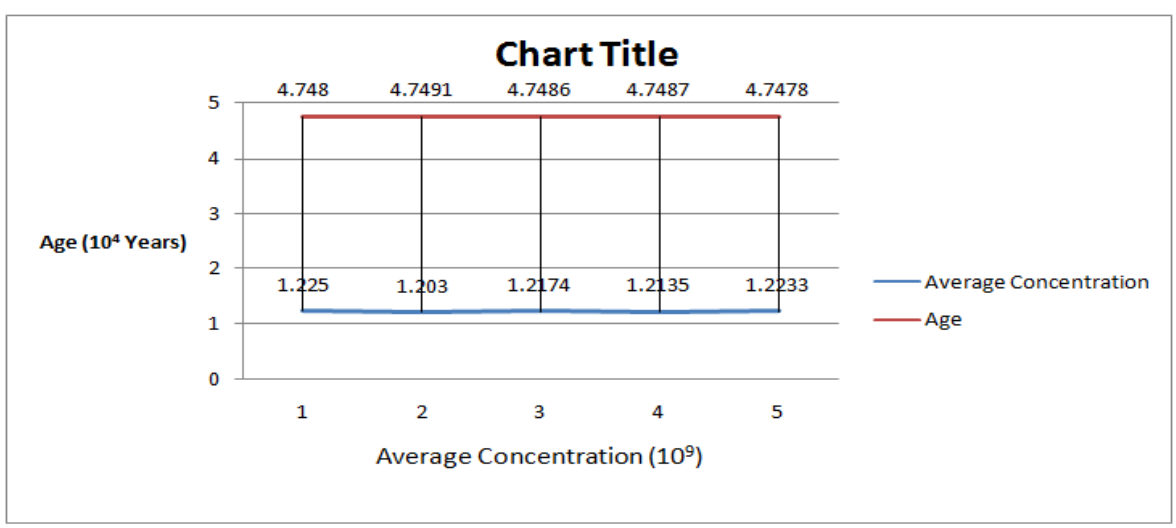

From R.P. Beukens' et-al, the intercomparison efforts of different samples of the Isotrace laboratory since 1984 have been tabulated as follows: (R.P. Beukens/NIMB-92 (1934)182-187).

\begin{tabular}{|l|l|l|l|l|l|}
\hline Sample & Age (Yrs) & Isotrace date (Yrs.) & Internal error & External error & Errors in the error \\
\hline GSC-3531 & $1950 \pm 50$ & 2004 & \pm 26 & \pm 24 & $( \pm 5)$ \\
\hline GSC-3055 & $6920 \pm 90$ & 7108 & \pm 20 & \pm 20 & $( \pm 3)$ \\
\hline QL-11288 & $4132 \pm 18$ & 4157 & \pm 17 & \pm 22 & $( \pm 4)$ \\
\hline QL-11312 & $6973 \pm 20$ & 7019 & \pm 24 & \pm 20 & $( \pm 4)$ \\
\hline
\end{tabular}


Study Of Cosmogenic Radionuclides Formed By Cosmic Ray Spallations In Quartz Samples

\begin{tabular}{|l|l|l|l|l|l|}
\hline IAEA-C2 & $7135 \pm 6$ & 7138 & \pm 24 & \pm 29 & $( \pm 4)$ \\
\hline IAEA-C5 & $11788 \pm 7$ & 11827 & \pm 47 & \pm 40 & $( \pm 10)$ \\
\hline Wood & $49339 \pm 400$ & 49300 & \pm 450 & \pm 450 & $( \pm 90)$ \\
\hline
\end{tabular}

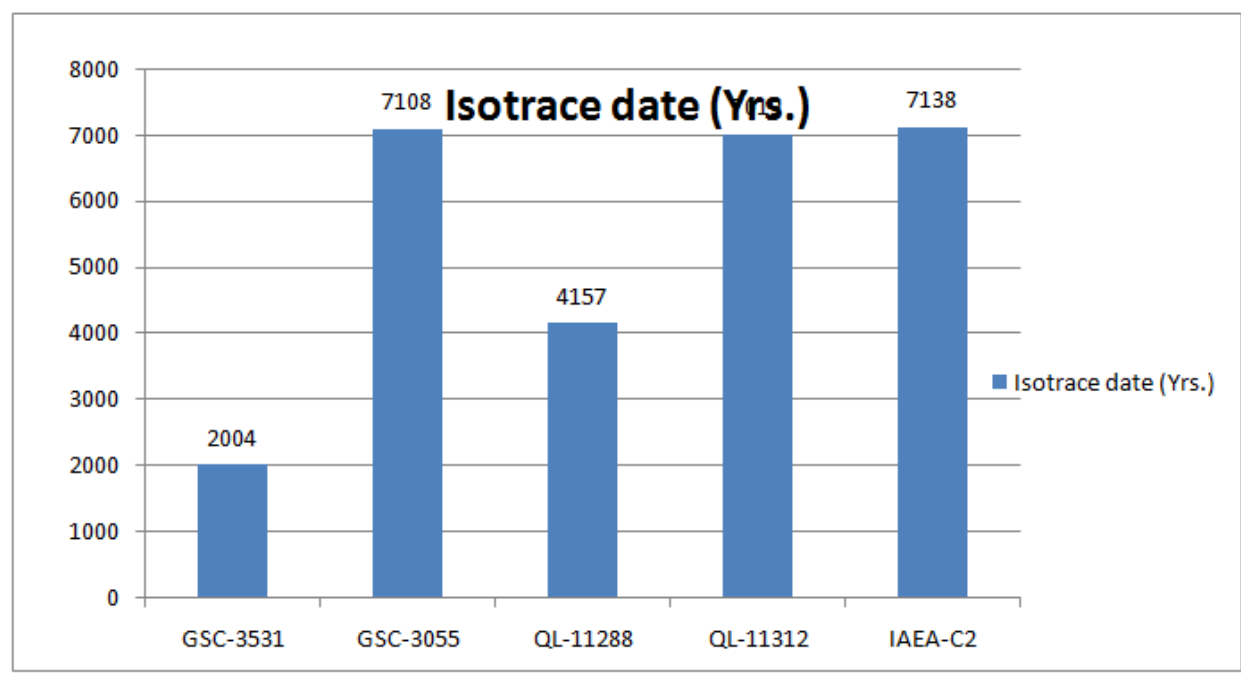

Further the statistical analysis of the ratios for standards was used to detect and diagnose more subtle problems with the system. Statistical comparison of the results from four targets. Statistical comparison of the results from four targets (Beuken) for $\mathrm{C}^{14}$ analysis.

\begin{tabular}{|l|l|l|l|l|}
\hline Target & Age (Years) & Isotrace date (Yrs-B.P.) & Internal error & External error \\
\hline Target -1 & 7298 & \pm 85 & \pm 71 & $( \pm 15)$ \\
\hline Target -2 & 7216 & \pm 88 & \pm 87 & $( \pm 16)$ \\
\hline Target -3 & 7157 & \pm 96 & \pm 118 & $( \pm 17)$ \\
\hline Target -4 & 7107 & \pm 77 & \pm 65 & $( \pm 14)$ \\
\hline
\end{tabular}

The graphs between the two results are found to be of similar nature. In ${ }^{14} \mathrm{C}$ analysis it was observed that the concentration of ${ }^{14} \mathrm{C}$ in the five samples is of the order of $10^{9}$ atoms $/ \mathrm{kg}$ and the ratio $\left({ }^{14} \mathrm{C} /{ }^{12} \mathrm{C}\right)$ was found to be the of the order of $10^{-14}$. Similarly after determination of ${ }^{36} \mathrm{Cl}$ from five samples of plateau region of Jharkhand the average concentration was found to be of the order of $10^{7}$ atoms $/ \mathrm{kg}$. and the ratio $\left({ }^{36} \mathrm{Cl} /{ }^{35} \mathrm{Cl}\right)$ was found to be of the order of $10^{-14}$. This showed that the efficiency of the machine for the isotopic analysis was of the order of $10^{-14}$, which makes the N.S.C. Pelletron a world class facility for Accelerator Mass Spectrometry. From R.P. Beuken's et.al. the inter comparison efforts of different samples of the isotrace laboratory since 1984 has brought about their age determination e.g. the sample GSC-3531 at the age 2004 years etc and also the statistical comparison of the different Targets of radioactive nuclei ${ }^{14} \mathrm{C}$ resulted into their age determination and they were found to be of the order of 7000 years approximately. N. Funaya et.al. discussed about a gas $\Delta \mathrm{E}-$ positive sensitive $\Delta \mathrm{E}-\mathrm{E}$ detector for A.M.S. studies in his experiment the Tsukuba A.M.S. systems has been used for the measurement of ${ }^{36} \mathrm{Cl}$. The ratio of ${ }^{36} \mathrm{Cl}$ to ${ }^{35} \mathrm{Cl}$. of the standard sample was measured to be $1.5 \times 10^{-}$ ${ }^{11}$. This ratio was about $50 \%$ larger than estimated ratio $9 \times 10^{-12}$. This discrepancy was due to the isobar ${ }^{36} \mathrm{~S}$ which were created mainly from the copper sample holder. A Tantalum sample holder was found to be useful to decrease ${ }^{36} \mathrm{~S}$ background and to improve the accuracy.

The limitations are as follows:

1. Sample preparations procedure needs to be developed such that beam current can be increased.

2. Isobaric interferences are needed to be minimized etc.

\section{Conclusion}

The nature of the quartz samples for the study of cosmogenic radionuclides almost looks alike and their graphs for the ratio of radio isotopes to the stable isotope and the average age of the sample by the dating through various isotopes are similar. 


\section{References}

[1] Alvarez, D.E., Abriola, D., Achterberg, E., Caputto, O.A., Ditada, M., Etchegoyen, A., Ferrero, A.M., Fernandez Niello, J.O., Marti, G.V., Pacheco, A.J., Ramirez, M., and Testoni, J.E., AMS program at the Tandem accelerator, Radiocarbon, 38, 2,1996.

[2] Balsley, D.R., Farwell, G.W., Grootes, P.M., and Schmidt, F.H., Ion source sample preparation techniques for carbon-14 AMS measurements, Nucl. Instrum.Methods Phys. Res., B29, 371987.

[3] Beukens, R.P., Procedures and precision of ${ }^{14}$ C AMS, Nucl .Instrum. Methods Phys. Res., B92,182,1994.

[4] Bierman, P.R., Using in-situ produced cosmogenic isotopes to estimate rates of landscape evolution: a review from the geomorphic perspective, J. Geophys. Res., 99(B13), 885,1994.

[5] Bierman, P.R., Gillespie, A., Caffee, M., and Elmore, D., Estimating erosion rates and exposure ages with ${ }^{36} \mathrm{Cl}$ produced by neutron activation, Geochim. Cosmochim.Acta, 59, 3779, 1995

[6] Bierman, P.R. Larsen, P., Clapp, E., and Clark, D., Refining estimates of ${ }^{10} \mathrm{Be}$ and ${ }^{26} \mathrm{Al}$ production rates.Radiocarbon, $38(1), 149,1996$.

[7] Bonani, G., Balzer, R. Hofmann, H.-F, Morenzoni, E. Nessi, M. Suter, M. and Wolfli, W. Properties of milligram size samples prepared for AMS ${ }^{14} \mathrm{C}$ dating at ETH. Nucl. Instrum. Methods Phys. Res. B5, 284, 1984

[8] Brown, E.T., Edmond, J.M., Raisbeck, G.M., Yiou, F. Kurz, M.D., and Brook, E.J. Examination of surface exposure ages of Antarctic moraines using in-situ produced ${ }^{10} \mathrm{Be}$ and ${ }^{26} \mathrm{Al}$, Geochim. CosmochimActa, 55, 2269, 1991.

[9] Brown, T.A., Farwell, G.W., and Grootes, P.M., Current status of the ${ }^{14} \mathrm{C}$ AMS program at the University of Washington, Nuci lustrum. Methods Phys. Res., B92, 16, 1994b.

[10] Chopra.S, Pawar. N.S., Nandi. T., et.al., New modifications in 15 UD pelletron at Nuclear Science Centre, Pramana,Vol. 59, No. 5,

[11] Jull, A.J.T., Lifton, N., Phillips, W.M., and Quade, J., Studies of the production rate of cosmic-ray produced "C in rock surfaces, Nucl. lustrum. Methods Phys. Res., B92, 308, 1994b.

[12] Kieser, W.E., Beukens, R.P., Kilius, L.R., Lee, H.W., and Litherland, A.E., Isotrace radiocarbon analysis- equipment and procedures, Nucl. instrum. Methods Phys. Res., B15, 718, 1986.

[13] Korff, S.A. and Mendell, R.B., Variations in radiocarbon production in the Earth's atmosphere, Radiocarbon, 22, 159, 1980.

[14] Sinha, R. R. and Nandi, T.K., Determination of cosmogenic radionuclide ${ }^{36} \mathrm{Cl}$ from quartz sample after separation from the isobars;Acta Ciencia Indica, Vol.xxxiv,2,207,2008 